\title{
The effect of inflation uncertainty on inflation: Stochastic volatility in mean model within a dynamic framework
}

\author{
Hakan Berument ${ }^{\mathrm{a}, *}$, Yeliz Yalcin ${ }^{\mathrm{b}, 1}$, Julide Yildirim ${ }^{\mathrm{b}, 2}$ \\ a Department of Economics, Bilkent University, 06800 Ankara, Turkey \\ b Department of Econometrics, Gazi University, 06500 Ankara, Turkey
}

\section{A R T I C L E I N F O}

\section{Article history:}

Accepted 15 May 2009

\section{JEL classification:}

C15

$\mathrm{C} 22$

E31

Keywords:

Inflation

Inflation uncertainty

Stochastic volatility models

\begin{abstract}
A B S T R A C T
This paper investigates the effect of inflation uncertainty innovations on inflation over time by considering the monthly United States data for the time period 1976-2006. In order to investigate the effect of inflation uncertainty innovation on inflation, a Stochastic Volatility in Mean model (SVM) has been employed. SVM models are generally used to capture the innovation to inflation uncertainty, which cannot be achieved in the framework of popular deterministic ARCH type of models. Empirical evidence provided here suggests that innovations in inflation volatility increases inflation persistently. This evidence is robust across various definitions of inflation and different sub-periods.
\end{abstract}

(c) 2009 Elsevier B.V. All rights reserved.

\section{Introduction}

The relationship between inflation and inflation uncertainty has drawn the attention of macroeconomists for many years both at the theoretical and the empirical level. However there is no consensus about the nature of the relationship between inflation and inflation uncertainty. Following Friedman (1977), Ball (1992) shows that higher inflation generates higher inflation uncertainty. Brunner and Hess (1993), and Grier and Perry $(1998,2000)$, for example, report evidence of a Friedman effect. Cukierman and Meltzer (1986), on the other hand, show that an increase in inflation uncertainty leads to an increase in inflation as it provides an incentive to the policymaker to create an inflation surprise in order to stimulate output growth. Whereas Holland (1995) argues that more inflation uncertainty can lead to a lower average inflation rate provided that the Central Bank tries to minimise the welfare losses arising from more inflation uncertainty.

\footnotetext{
is We would like to thank to Yilmaz Akdi, Manabu Asai, Pok-sang Lam and Nadir Öcal for their valuable suggestions, Furkan Emirmahmutoglu for the excellent research assistance and the Turkish Scientific and Technological Research Council for their partial financial support (SOBAG-105K006).

* Corresponding author. Tel.: +90 312290 2342; fax: +90 3122665140. E-mail addresses: berument@bilkent.edu.tr (H. Berument), yyeliz@gazi.edu.tr (Y. Yalcin), julide@gazi.edu.tr (J. Yildirim).

URL's: http://www.bilkent.edu.tr/ berument (H. Berument), http://yyelizyalcin.googlepages.com (Y. Yalcin).

${ }^{1}$ Tel.: +90 312 2161304; fax: +90 3122132036

2 Tel.: +90 312 2161301; fax: +90 3122132036 .
}

Early studies, focusing on the variability, as opposed to uncertainty, of inflation that test for the correlation between inflation and inflation variability, agree that inflation variability is positively correlated with inflation. Following the seminal paper of Engle (1982) on Autoregressive Conditional Heteroskedasticity (ARCH) models and subsequently the Generalized Autoregressive Conditional Heteroscedasticity (GARCH) extension by Bollerslev et al. (1994), inflation uncertainty is generally proxied by the conditional variance of unanticipated shocks to inflation. Subsequent empirical studies report mixed evidence regarding the association between inflation and inflation uncertainty using a variety of methodologies. These studies, however, usually examine the inflation-inflation uncertainty relationship at either short run or long-run horizons. Ball and Cecchetti (1990) argue that this relationship may differ between short-run and long-run horizons.

As an alternative to GARCH models that capture this time-varying autocorrelated volatility process, the Stochastic Volatility (SV) models have been employed to explain the well documented time varying volatility in empirical research. SV models allow for a stochastic element in the time series evolution of the conditional variance process. Danielsson (1994), Geweke (1994), and Kim et al. (1998) give empirical evidence supporting the successes of the lognormal SV model relative to GARCH-type models.

This paper aims to investigate the direct relationship between inflation and inflation uncertainty the United States over the period 1976-2006 using monthly data. Unlike the existing literature where the inflation uncertainty is generally proxied by GARCH models, inflation uncertainty in this study is modeled by SV model with state space approach to capture the dynamics. This paper is organized as 
follows. The next section discusses the inflation and inflation uncertainty relationship. Section 3 presents the modeling approach employed in this study. Estimation results are sum`marized in Section 4. Finally, Section 5 concludes.

\section{Inflation and inflation uncertainty}

The uncertainty about future inflation has been one of the most important costs of inflation, as it clouds the decision making of economic agents. The uncertainty of an economic variable can be defined as its unpredictable volatility, which is the sum of both predictable and unpredictable components (Crawford and Kasumovich, 1996; Grier and Perry, 1998). Evans and Wachtel (1993) argue that there are two sources of inflation uncertainty: "regime uncertainty" and "certainty equivalence." Considering the first category, future inflation may be uncertain as agents are not sure about the characteristics of the current policy regime or about the future policy regime, if there is a possibility that the regime will change. Even if the agents have all the information about the current policy regime, there would still be uncertainty about the structure of the inflation process within each regime. Two interesting implications stem from this decomposition: Inflation uncertainty will change over time for a country as agents use new information to update their perceptions of the current policy regime. Moreover, the international differences in average levels of uncertainty would lead to differences in monetary policy regimes.

The relationship between inflation and inflation uncertainty is important for policy makers because if systematic inflation has any real effects, governments can influence economic performance through monetary policy. Inflation uncertainty has both ex ante and ex post effects in that it causes economic agents to make decisions that are different from the ones they would make otherwise, considering their both future and past economic activities. Golob (1994) notes that inflation uncertainty may have an adverse affect on the economy ex ante as it affects financial markets by raising long-term interest rates and consequently reducing investment spending (Huybens and Smith, 1999). Thus, investors would find it more difficult to make reliable decisions about investments in longer-term financial instruments. Boyd et al. (2001) point out that higher rates of inflation can impair the effective functioning of the financial sector, including financial markets, even in low-to-moderate inflation economies. The ex post effects, on the other hand, occur when inflation differs from what had been expected, which may lead to a transfer of wealth whenever the payments in a contract are specified in nominal terms.

There are two conflicting views concerning the relationship between inflation and inflation uncertainty. ${ }^{3}$ The direction of this relationship is crucial for a successful implementation of a monetary policy to control inflation. A number of theoretical models, where monetary policy often plays a prominent role, predict that uncertainty about future inflation is positively related with inflation. Similar to Okun (1971) and Friedman (1977) who highlight the positive relationship between inflation and inflation uncertainty, Ball (1992) focuses on uncertainty about the monetary policy regime. Ball (1992) formalizes Friedman's argument in the context of an asymmetric information game between the public and the policy marker. In Ball's model, if current inflation is low, the inflation uncertainty will be low as agents believe that the monetary authorities will seek to maintain the low inflation. However, if the current rate of inflation raises due to an unexpected shock, there is uncertainty about whether the authorities are willing to accept the temporary reduction in output that would accompany a disinflationary policy. Accordingly, inflation uncertainty will increase at higher rates of inflation due to the uncertainty concerning future monetary policy causes. Similarly, Golob (1994) claims that another factor, that contributes to the positive

\footnotetext{
3 See Holland, 1993; Grier and Perry, 1998 for review of literature.
}

relationship between inflation and inflation uncertainty is that the timing of the disinflationary policy action is uncertain.

An alternative explanation for a positive relationship between inflation and inflation uncertainty is provided by Holland (1993) who considers a case in which agents are unsure about the price-level effects of a given change in the quantity of money. The implication of this parameter uncertainty is that inflation uncertainty increases at higher rates of expected inflation. In addition to the uncertainty of the impact of monetary policy on inflation, the speed with which monetary policy actions are transmitted to inflation varies over time. Thus, even the agents have all the information regarding the stance of monetary policy, the complexity of predicting the magnitude and the speed with which prices will respond to monetary policy creates inflation uncertainty.

Contrary to the causation link proposed by Friedman-Ball view, Cukierman and Meltzer (1986) and Cukierman (1992) claim that higher inflation uncertainty leads to a raise in the optimal inflation rate. They argue that if the money supply process has a stochastic element and the public is uncertain about the objective function of the policymaker, higher inflation uncertainty raises the optimal inflation rate by increasing the incentive for the policy maker to create inflation surprise to stimulate real economic activity within the traditional Barro-Gordon framework. Thus in their models, increased inflation uncertainty leads to a raise in average inflation. Holland (1995), Grier and Perry (1998), Berument and Dinçer (2005) provide empirical evidence for this.

In empirical studies investigating the inflation-inflation uncertainty relationship, a measure of uncertainty needs to be employed. As the measurement of the inflation uncertainty is subjective and there is only a limited amount of quantitative information on long-term inflation expectations, generally proxy variables are employed. Early studies commonly used the statistical variability in average long-run inflation as a proxy variable for inflation uncertainty, such as moving standard deviation of inflation (Fischer, 1981). One standard criticism of these statistical measures of uncertainty is that higher variability need not necessarily imply higher uncertainty, which would be the case only if agents don't possess the relevant information to predict part of the increased variability. An alternative measure would be the dispersion in long-run inflation expectations from a survey of forecasters, businesses, or households (Johnson, 2002). The validity of the survey measures of inflation uncertainty is generally undermined due to the fact that they do not take account of the level of uncertainty of each individual forecaster (Grier and Perry, 2000). However, Zarnowitz and Lambros (1987) notes that there is a positive correlation between the dispersion of inflation forecasts across survey respondents and the uncertainty of each individual forecaster.

With the development of econometrics, as the literature turned to time series tests, inflation uncertainty is generally proxied by the estimated one-step ahead conditional variance from the Generalized Autoregressive Conditional Heteroscedasticity (GARCH) models ${ }^{4}$ of inflation estimates a model of the variance of unpredictable innovations in inflation, rather than simply calculating a variability measure from the past outcomes (moving standard deviation) or conflicting individual forecasts. One advantage of using the GARCH estimation is that it offers a direct test of statistical significance of time variation of conditional variance whereas survey based measure does not (Grier and Perry, 1998; Evans, 1991). However the main drawback of GARCH modeling is that conditional volatility models like GARCH ignores the existence of structural instability due to changes in regimes. Even though they measure conditional variation of volatility, the unconditional volatility remains constant. Moreover, they model the inflation series as comprising of both a temporary and a permanent component. However, the separation of this kind for the inflation series

\footnotetext{
${ }^{4}$ For surveys on GARCH models please see Bera and Higgins (1993), Bollerslev et al. (1994) and Diebold and Lopez (1995).
} 
Table 1

Estimation results for SV model.

\begin{tabular}{|c|c|c|c|c|c|}
\hline$y_{t}$ & $\begin{array}{l}\text { Constant } \\
0.0899[0.0607: 0.1191]\end{array}$ & $\begin{array}{l}y_{t-1} \\
0.4528[0.3801: 0.5276]\end{array}$ & $\begin{array}{l}y_{t-2} \\
0.0176[0.0113: 0.02731]\end{array}$ & $\begin{array}{l}\sigma^{*} 2 \exp \left(h_{t}\right) \\
1.6962[0.5892: 2.8032]\end{array}$ & $\begin{array}{l}\exp \left(0.5 h_{t}\right) \varepsilon_{t} \\
0.0392[0.0267: 0.0576]\end{array}$ \\
\hline$h_{t}$ & $\begin{array}{l}h_{t-1} \\
0.9685 \text { [0.9654:0.9713] }\end{array}$ & $\begin{array}{l}\eta_{t} \\
0.0419[0.0230: 0.0762]\end{array}$ & & & \\
\hline $\begin{array}{l}n L: 62.401 \\
Q(12): 0.2366(0.6266)\end{array}$ & I AIC: -110.803 & $\begin{array}{l}\text { SBC: }-83.503 \\
Q(24): 0.8639(0.3527)\end{array}$ & HQ: -42.204 & & \\
\hline
\end{tabular}


$q \ln (T)$ and $-2(\ln L)+2 q \ln (T)$. Where $q$ is the total number of estimated parameters, $T$ is the total number of observations.

$Q(i)$ reports Wooldridge (1991)'s robust LM test for $i$ lag and $p$-values are reported next to test statistics in parenthesis for the $i$ th lag.

suggested by Ball and Cecchetti (1990) allows the authors to study the impact of uncertainty on each of these components.

In recent years stochastic volatility models have become a competitive alternative to GARCH models, even though its empirical application has been limited. The studies in the literature investigating inflation-inflation uncertainty have generally adopted a static approach in that, the variance equation does not contain an innovation and the volatility changes deterministically. However, shocks in the volatility may lead the dynamic effects in other economic variables, necessitating a dynamic framework modeling, such as SV models that allows variance to be a random variable and the volatility changes stochastically rather than deterministically. The GARCH model allows for only a single error term, whereas, the SV model assumes two error processes, implying that the SV model can provide a better in-sample fit see Kim et al. (1998), and perhaps also better forecasts. Another advantage of the dynamic modeling is that it enables the researcher to assess how the inflation uncertainty will effect the inflation itself. If it is persistent, then inflation should better be reduced progressively. In cases where both inflation and inflation uncertainty are persistent, modeling static relationships using ARCH/ GARCH may give misleading results. Accordingly, Elder (2004) point this issue and examines the effects of inflation uncertainty on real economic activity by employing MGARCH-in-mean-VAR method. Therefore, we will try to assess the relationship between inflation and inflation uncertainty by using Stochastic Volatility (SV) model $^{5}$ as a dynamic framework, following Koopman and Uspensky (2002).

\section{Model}

There are two general classes of volatility models that have been generally employed in the literature. The first type formulates the conditional variance directly as a function of observables, for examples $\mathrm{ARCH}, \mathrm{GARCH}$ specifications. The second general class formulates models of volatility that are not functions purely of observables. These models could be called latent volatility or SV models. The mean equation for both models can be written as

$y_{t}=\mu_{t}+\sigma_{t} \varepsilon_{t}, \quad \varepsilon_{t} \sim \mathrm{NID}(0,1)$

$\mu_{t}=a+\sum_{i=1}^{k} b_{i} x_{i, t}$

where $\mu_{t}$ is the (conditional) mean, $x_{i, t}$ denotes a set of exogenous variables at time $t, a$ is a constant term and $b_{1}, b_{2}, \ldots b_{k}$ are regression coefficients. The error term $\varepsilon_{t}$ is independently and identically normally distributed with zero mean and unit variance. Therefore, the mean adjusted series is defined as white noise with unit variance multiplied by the volatility process. SV models specify the unknown volatility changes stochastically over time. SV models, that contain an

\footnotetext{
${ }^{5}$ For surveys of SV models, see among others Taylor (1994), Ghysels et al. (1996) and Shepard (1996).
}

unobserved variance component and the logarithm of the variance components, are modeled directly as a linear stochastic process, such as an autoregressive model. Thus, SV models can be considered as an alternative to the ARCH models where the mean and volatility equations are estimated simultaneously.

The variance equation of the SV model can be expressed as

$\sigma_{t}^{2}=\sigma^{* 2} \exp \left(h_{t}\right)$

where $\sigma^{*}$ is a positive scaling factor

The volatility process $\sigma_{t}^{2}$ is defined as the product of the positive scaling factor $\sigma^{*}$ and the exponential of the stochastic volatility process $h_{t}$. Here it is assumed that $h_{t}=\ln \left(\sigma_{t}^{2} / \sigma^{* 2}\right)$ follows an autoregressive model of order 1 :

$h_{t}=\phi h_{t-1}+\sigma_{\eta} \eta_{t}, \quad \eta_{t} \sim \mathrm{NID}(0,1)$

Where for the stationarity of $h_{t}$, the persistence parameter $(\phi)$ is restricted to be less than one in a absolute value $(|\phi|<1) .{ }^{6}$ It is also assumed that the two disturbances $\varepsilon_{t}$ and $\eta_{t}$ are mutually uncorrelated contemporaneously and at all lags. Since the term $\ln \sigma^{* 2}$ is constant, the logarithm of volatility process does not include an additional intercept term. Thus, the SV model can be rewritten as follows:

$$
\begin{aligned}
\ln \sigma_{t}^{2} & =\ln \sigma^{* 2}+h_{t} \\
& =\ln \sigma^{* 2}+\phi\left(\ln \sigma_{t-1}^{2}-\ln \sigma^{* 2}\right)+\sigma_{\eta} \eta_{t} \\
& =(1-\phi) \ln \sigma^{* 2}+\phi \ln \sigma_{t-1}^{2}+\sigma_{\eta} \eta_{t}
\end{aligned}
$$

SV and ARCH models require simultaneous estimation of the mean and variance specifications (see Pagan and Ullah, 1988). ARCH models can be considered because variance is modeled conditionally on the information up to and including time $t-1$ and only the mean equation has a disturbance term. On the other hand, for the SV model, the deviation of $y_{t}$ from the mean is captured by a function of two disturbance.

Koopman and Uspensky (2002) extended the stochastic volatility model by allowing the variance as one of the determinants of the mean specification-SV in Mean (SVM) model. Thus, the mean equation can be rewritten as:

$\mu_{t}=a+\sum_{i=1}^{k} b_{i} x_{i, t}+d \sigma^{* 2} \exp \left(h_{t}\right)$

\footnotetext{
${ }^{6}$ The lag length of SV model is selected one by using Schwarz Bayesian Criteria during the estimations. However, we also consider different lag lengths as a part of robustness of our estimates.
} 
CPI For All Urban Consumers: All Items



Fig. 1. Effects of inflation volatility shock to the inflation 1976:01-2006:07.

where $d$ is a risk premium coefficient and captures the volatility-inmean effect. In order to capture the inflation dynamics, parallel to Grier and Perry (2000) and Berument et al. (2005), the mean equation is modeled as an AR process in this study. Thus, SVM model is defined in Eqs. (1), (3), (4) and (6) can be written as

$$
y_{t}=a+\sum_{i=1}^{k} b_{i} y_{t-i}+d \sigma^{* 2} \exp \left(h_{t}\right)+\sigma^{*} \exp \left(0.5 h_{t}\right) \varepsilon_{t}, \quad \varepsilon_{t} \sim \mathrm{NID}(0,1)
$$

$h_{t}=\phi h_{t-1}+\sigma_{\eta} \eta_{t}, \quad \eta_{t} \sim \mathrm{NID}(0,1)$

Various estimation procedures have been used for the SV models: the Generalized Method of Moments (Melino and Turnbull, 1990); the Quasi Maximum Likelihood (Harvey et al., 1994; Ruiz, 1994); the Efficient Method of Moments (Gallant et al., 1997) and Markov-Chain Monte Carlo (Jacquier et al., 1994; Andersen et al., 1999; Kim et al., 1998). In this paper, we used exact maximum likelihood methods using Monte Carlo importance sampling techniques to estimate the parameters of the SVM model. The three advantages of this method can be named as follows: (i), this method exploits the structure of the specification to improve the speed of the convergence by integrating the Kalman filter; (ii), the dimension of state is increased by approximating the log likelihood (see, Shephard and Pitt, 1997, for details); and (iii) it can be extended to a multivariate case by using multivariate Taylor series expansion. Thus, we could include explanatory variables in the mean equation and estimate their coefficients simultaneously with the parameters of the volatility process.

\section{A CPI for All Urban Consumers: All Items Less Food \& Energy}

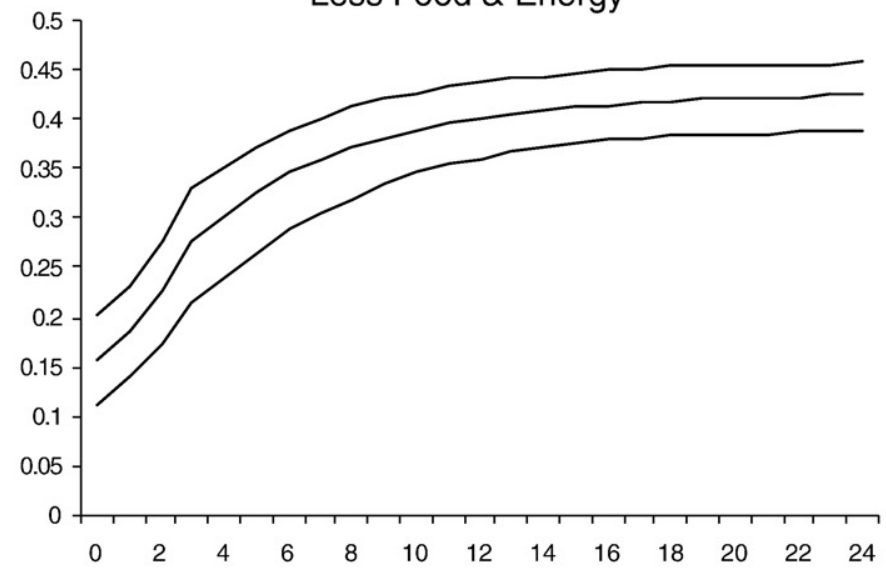

\section{PCE Chain-type Price Index}

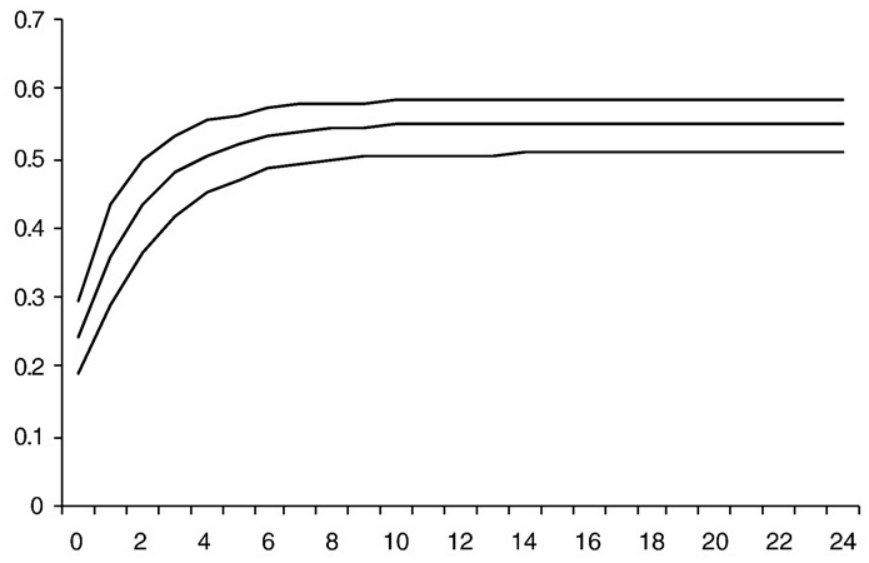

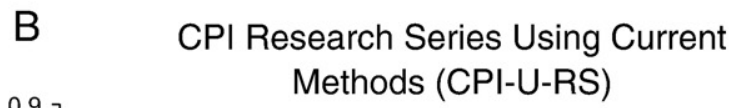



\section{PCE Chain-type Price Index Less Food and Energy}

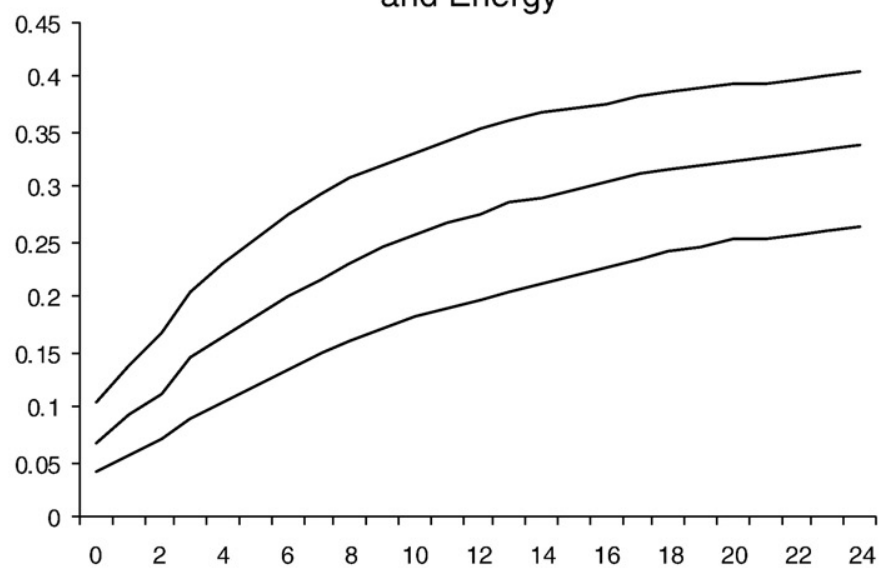

Fig. 2. Effects of inflation volatility shock to the inflation 1976:01-2006:07. 
The likelihood function of the SV model specification can be constructed by using the simulation method developed by Shephard and Pitt (1997) and Durbin and Koopman (1997). Consider the volatility process of an SV model presented in Eq. (4), the non-linear relation between logarithm of the volatility measure $\left(h_{t}\right)$ and the observation equation $\left(y_{t}\right)$ does not allow the computation of the likelihood by linear methods such as the Kalman filter. The likelihood function for the SV model can be written as:

$L(\psi)=p\left(\frac{y}{\psi}\right)=\int p\left(\frac{y, \theta}{\psi}\right) \mathrm{d} \theta=\int p\left(\frac{y}{\theta, \psi}\right) p\left(\frac{\theta}{\psi}\right) \mathrm{d} \theta$

Where $\theta=\left(h_{1}, \ldots, h_{T}\right)^{\prime}$ and $\psi=\left(\phi, \sigma_{\eta}, \sigma_{\varepsilon}\right)^{\prime}$. An efficient evaluation of such an expression is to use importance sampling (see Ripley, 1987). A simulation tool is needed to sample from an importance density $\hat{p}(y / \theta, \psi)$, which is preferred to be as close as possible to the true density $p(y / \theta, \psi)$. A choice for the importance density is conditional upon density function since in the case of Gaussian it is relatively straightforward to sample from $p(y / \theta, \psi)=g(y / \theta, \psi)$ using simulation smoothers such as the ones developed by De Jong and Shephard (1995) and Durbin and Koopman (2002). Hol and Koopman (2000) and Asaf (2006) provide a guideline for the construction of an importance model and the likelihood function for the SV model using this model. One may also visit Koopman and Uspensky (2002) for details. In order to estimate the model we used SsfPack package written in the Ox language by Koopman et al. (1999). ${ }^{7}$

\section{Empirical evidence}

The seasonally adjusted monthly data of the United States Consumer Price Index for All Urban Consumers is used to calculate inflation. The sample covers the period 1976:01-2006:07. ${ }^{8}$ Inflation is measured by the logarithmic first difference of the consumer price index. In order to specify a model to assess the effect of inflation volatility on inflation, SVM model defined in Eqs. (7.a) and (7.b) are estimated jointly. The Schwarz Bayesian Criteria (SBC) is used to determine the lag length of the model. Table 1 reports the SVM model estimates, where the parameters of the mean (inflation) are presented in the first part of the Table 1 together with their 95\% confidence intervals. The second part of the Table 1, on the other hand, reports the estimates of the variance specification.

The mean (inflation) specification includes two lagged values of inflation and volatility of the inflation. Volatility specification (in logarithm) includes only the lagged values of logarithm of the inflation volatility. All the parameter estimates are statistically significant. Moreover, the volatility persistence parameter estimate (lagged value of the volatility in the volatility specification) for the series is statistically significant and less than one in absolute value implying that $h_{t}$ is a stationary.

Empirical evidence in Table 1 suggests that the inflation volatility explains the behavior of the inflation, not the other way around contemporaneously. Alternative specifications of the relationship between inflation and inflation volatility are also considered, where, various lags of inflation and its volatility are allowed to enter the inflation specification as well as various lags of inflation and its volatility are allowed to enter the volatility specification. ${ }^{9}$ Moreover, different

\footnotetext{
7 The codes might be downloaded from http://www.econ.vu.nl/koppman/sv/.

${ }^{8}$ The data was gathered from FRED of St Louis Fed: http://research.stlouisfed.org/fred2.

${ }^{9}$ To be particular we also estimate the following models:

$y_{t}=a+\sum_{i=1}^{k} b_{i} y_{t-i}+\sum_{s=0}^{m} d_{s} \sigma^{* 2} \exp \left(h_{t-s}\right)+\sigma^{*} \exp \left(0.5 h_{t}\right) \varepsilon_{t}, \quad \varepsilon_{t} \sim \mathrm{NID}(0,1)$

$h_{t}=\sum_{j=1}^{p} \phi_{j} h_{t-j}+\sum_{i=1}^{n} \delta_{i} y_{t-i}+\sigma_{\eta} \eta_{t}, \quad \eta_{t} \sim \mathrm{NID}(0,1)$
}

However, in order to save space, these estimates are not reported here but they are available to interested readers upon request. definitions of inflation and alternative sub-periods have also been examined. Among these estimates, the model, where inflation is introduced to inflation volatility specifications, gives some statistically significant coefficients at the $5 \%$ level but they have alternating signs. Even if these specifications are not suggested by SBC, these alternative specifications are elaborated and impulse responses for these specifications are derived (calculation of the impulse will be discussed below). Empirical analysis suggests that the effect of inflation on inflation volatility is unstable but the effect of inflation volatility on inflation is robust.

The LM test suggested by Wooldridge (1991) for 12 and 24 periods are considered for autocorrelation of the standardized residuals. The null hypothesis that the first 12 and 24 autocorrelation coefficients of the standardized residuals $\left(\varepsilon_{t}\right)$ are equal to zero cannot be rejected at the $5 \%$ significance level. Furthermore, the Jarque-Berra Normality test statistic cannot reject the normality at the $5 \%$ level. Thus, these two classes of tests support the validity of model specification.

In order to assess the effect of inflation volatility on inflation within the SVM framework reported in Table 1, an impulse response function has been analytically derived. The impulse-response function is frequently regarded as implying a causal affect, whereas Hamilton (1994) notes that the most sound interpretation of an empirical impulse-response function is the revision in the conditional forecast of $y_{t+k}$ given a primitive shock. The impulses of $y_{t+k}$ for a given shock to $\eta_{t}$ are $\partial E\left(y_{t+k} \mid \varepsilon, \eta, \Omega_{t}\right) / \partial \eta_{t}$ where $\Omega_{t}$ is the information set at time $t$. Deriving impulse response function for Autoregressive-SVM model
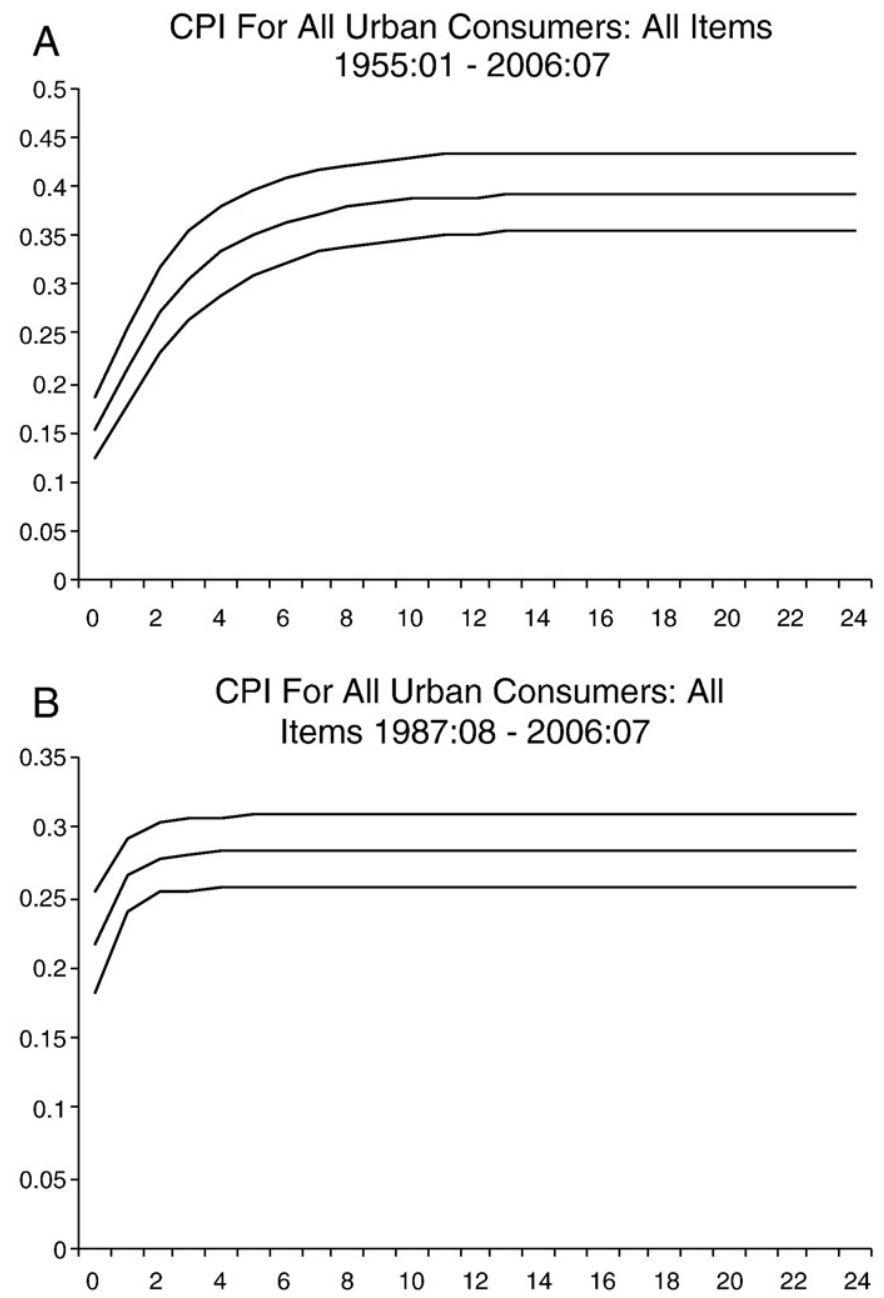

Fig. 3. Effects of inflation volatility shock to the inflation. 


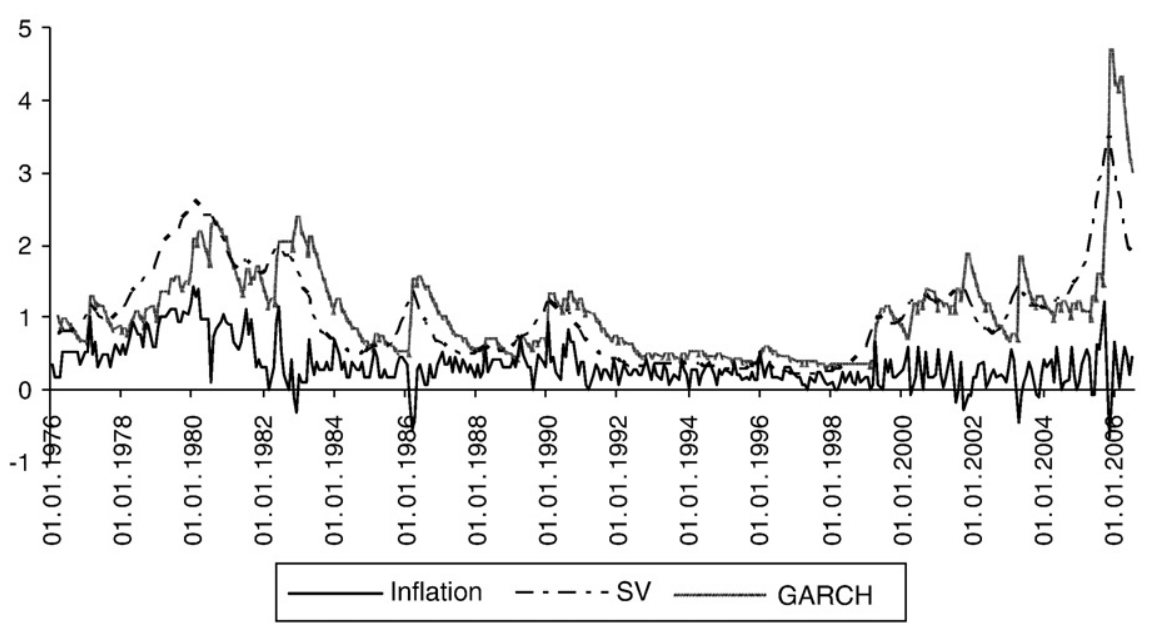

Fig. 4. Inflation, and stochastic in mean and $\operatorname{GARCH}(1,1)$ in mean specifications of volatility.

is more complicated than that for traditional Autoregressive models because these shocks also affect $y_{t}$ not only through mean but with variance (Elder, 2004). The MA representation of the SVM model that we estimated can be written as

$$
\begin{aligned}
y_{t+k}=a & +b_{1} y_{t+k-1}+b_{2} y_{t+k-2}+d \sigma_{t+k}^{2}+\sigma_{t+k} \varepsilon_{t+k} \\
=a & +\left(b_{1}+b_{2} L\right) y_{t-1}+d \sigma_{t+k}^{2}+\sigma_{t+k} \varepsilon_{t+k} \\
=a & +\left(b_{1}+b_{2} L\right)\left(a+b_{1} y_{t+k-2}+b_{2} y_{t+k-3}+d \sigma_{t+k-1}^{2}\right. \\
& \left.+\sigma_{t+k-1} \varepsilon_{t+k-1}\right)
\end{aligned}
$$

where $L$ is the lag operator, then by substitution Eq. (9) can be rewritten as follows:

$$
\begin{aligned}
= & a\left[1+\left(b_{1}+b_{2}\right)+\left(b_{1}+b_{2}\right)^{2}+\ldots\right] \\
& +\left[d \sigma_{t+k}^{2}+\left(b_{1}+b_{2} L\right) \sigma_{t+k-1}^{2}+\left(b_{1}+b_{2}\right)^{2} \sigma_{t+k-2}^{2}+\ldots\right] \\
& +\left[\sigma_{t+k^{\varepsilon}} \varepsilon_{t+k}+\left(b_{1}+b_{2} L\right) \sigma_{t+k-1} \varepsilon_{t+k-1}+\left(b_{1}+b_{2}\right)^{2} \sigma_{t+k-2^{\varepsilon_{t}+k-2}}+\ldots\right] \\
= & a \sum_{i=0}^{\infty}\left(b_{1}+b_{2}\right)^{i}+d \sum_{i=0}^{\infty}\left(b_{1}+b_{2} L\right)^{i} \sigma_{t+k-i}^{2} \\
& +\sum_{i=0}^{\infty}\left(b_{1}+b_{2} L\right)^{i} \sigma_{t+k-i^{\varepsilon} \varepsilon_{t}+k-i}
\end{aligned}
$$

If $b_{1}+b_{2} L$ has the characteristics roots outside of the unit circle and $|\phi|<1$, then Eq. (10) can be expressed as:

$$
\begin{aligned}
y_{t+k}= & \frac{a}{1-b_{1}-b_{2}}+d \sum_{i=0}^{\infty}\left(b_{1}+b_{2} L\right)^{i}\left\{\sigma^{* 2} \exp \left(\frac{\sigma_{\eta} \eta_{t+k-i}}{1-\phi L}\right)\right\} \\
& +\sum_{i=0}^{\infty}\left(b_{1}+b_{2} L\right)^{i}\left\{\sigma^{* 2} \exp \left(\frac{\sigma_{\eta} \eta_{t+k-i}}{1-\phi L}\right)\right\}^{0.5} \varepsilon_{t+k-i}
\end{aligned}
$$

Taking the partial derivative $\partial E\left(y_{t+k} \mid \varepsilon, \eta, \Omega_{t}\right) / \partial \eta_{t}$ yields the impulse responses of $y$ to a unit shock to $\eta_{t}$ for different time period of $k$. The confidence intervals based on the bootstrap simulation with 250 trials are calculated at the 95\% level to implement statistical inference. ${ }^{10}$

In order to capture the instantaneous and dynamic effects of inflation volatility shock to inflation, the impulse responses are gathered from our estimated speciation. Impulse responses along with confidence bands for CPI for all urban consumers are plotted out in Fig. 1 for 24 months. The middle line is the median of the draws and

\footnotetext{
${ }^{10}$ One may visit Koop et al. (1996) and Potter, S. (2000) for the calculation of impulse responses for more general of models.
}

upper and lower lines are for the confidence bands. The impulse responses suggest that the initial impact of one standard deviation shock in inflation volatility to inflation is positive and statistically significant. Empirical analysis suggests that inflation increases for six periods and stabilizes at 0.462 , after the initial shock. Thus, a one-time inflation volatility shock has a permanent effect on the level of inflation.

In order to investigate the robustness of the results, alternative specifications are considered. First we consider four different price measures to calculate inflation: (i) Consumers: All Items Less Food and Energy; (ii) Consumer Price Index Research Series Using Current Methods (CPI-U-RS) ${ }^{11}$; (iii) Personal Consumption Expenditures: Chain-type Price Index; and (iv) Personal Consumption Expenditures Chain-Type Price Index Less Food and Energy. Panel A to D of Fig. 2, report the impulse responses of inflation to one standard deviation shock in inflation volatility. It appears that the basic result from Fig. 1 is robust. As a second set of robustness test, alternative time spans are considered for our benchmark inflation definition - United States Consumer Price Index for All Urban Consumers. Fig. 3 reports the impulse responses for two different sample periods. The first sample uses the data for the post Korean War (1955:01-2006:07) and the second sample uses data for the Greenspan era (1987:08-2006:07). The basic result from Fig. 1 is still robust.

Thus, the empirical evidence provided in this paper suggests that innovations in inflation uncertainty accelerates inflation (parallel to Cukierman and Meltzer, 1986). As a separate exercise, we estimate the effect of the inflation on inflation volatility. The estimates suggest that inflation affects inflation uncertainty depending on the time frame and inflation variable that is considered. However, the further investigation of this issue is left to a further study.

Even if ARCH types of models do not incorporate shocks to the volatility, Engle (1982) type ARCH models are also considered. Accordingly, volatility is specified as Generalized-ARCH $(1,1)$ in mean process where the inflation is modeled with a constant term, its two lags and conditional variance of inflation. Generalized-ARCH $(1,1)$ and SVM measures of volatility as well as inflation series are reported in Fig. 4. Both of the volatility measures suggest that inflation volatility was low around 1990s and there has been an increase after 2005. Even if both movements of the volatility measures are very close, the figure suggests that SV measures lead to a GeneralizedARCH $(1,1)$ specification. ${ }^{12}$

\footnotetext{
11 The observations on CPI-RS ends 2005:12.

12 When the conditional variance is estimated with a $\operatorname{EGARCH}(1,1)$ in mean specifications, the basic result of the paper was robust.
} 


\section{Conclusion}

This paper assesses the effect of inflation uncertainty on inflation by using Stochastic Volatility in Mean model within a dynamic framework for the United States by employing monthly data for the period 1976:01 to 2006:07. The stochastic volatility in mean model is used to construct measures of monthly inflation uncertainty. Furthermore, an impulse response function has been analytically derived in order to assess this relationship. Empirical evidence reported suggests that shock to inflation volatility increases inflation, confirming the findings of Cukierman and Meltzer (1986), Devereux (1989), Cukierman (1992). This effect appears to be robust to various measures of inflation and sample periods.

\section{Appendix A. Supplementary data}

Supplementary data associated with this article can be found, in the online version, at doi:10.1016/j.econmod.2009.05.007.

\section{References}

Andersen, T., Chung, H., Sorensen, B.E., 1999. Efficient method of moments estimation of a stochastic volatility model: a Monte Carlo study. Journal of Econometrics 91, 61-87.

Asaf, A., 2006. The stochastic volatility in mean model and automation: evidence from TSE. The Quarterly Review of Economics and Finance 46, 241-253.

Ball, L., 1992. Why does high inflation raise inflation uncertainty? Journal of Monetary Economy 29, 371-388.

Ball, L., Cecchetti, S.G., 1990. Inflation and uncertainty at short and long horizons. Brookings papers on Economic Activity I, 215-254.

Bera, A.K., Higgins, M.L., 1993. ARCH models: properties, estimation and testing. Journal of Economic Surveys 7, 305-366.

Berument, H., Dincer, N.N., 2005. Inflation and inflation uncertainty in the G-7 countries. Physica A 348, 371-379.

Berument, H., Kilinc, Z., Ozlale, U., 2005. The missing link between inflation uncertainty and interest rates. Scottish Journal of Political Economy 52 (2), 222-241.

Bollerslev, T., Engle, R.F., Nelson, D.B., 1994. ARCH Models. In: Engle, R.F., McFadden, D.L. (Eds.), Handbook of Econometrics, 4. Elsevier Science, Amsterdam, pp. 2959-3038.

Boyd, J., Levine, R., Smith, B., 2001. The impact of inflation on financial sector performance. Journal of Monetary Economics 47, 221-248.

Brunner, A.D., Hess, G., 1993. Are higher levels of inflation less predictable? A statedependent conditional heteroskedasticity approach. Journal of Business and conomic Statistics 11, 187-197.

Crawford, A., Kasumovich, M., 1996. Does inflation uncertainty vary with the level of inflation? Bank of Canada Working Paper No. 96-9.

Cukierman, A., 1992. Central Bank Strategy, Credibility and Independence: Theory and Evidence. MIT Press, Cambridge, Mass.

Cukierman, A., Meltzer, A., 1986. A theory of ambiguity credibility and inflation under discretion and asymmetric information. Econometrica 54, 1099-1128.

Danielsson, J., 1994. Stochastic volatility in asset prices, estimation with simulated maximum likelihood. Journal of Econometrics 64, 375-400.

De Jong, P., Shepard, N., 1995. The simulation smoother for time series models. Biometrika 82, 339-350.

Devereux, M., 1989. A positive theory of inflation and inflation variance. Economic Inquiry $27,105-116$.

Diebold, F.X., Lopez, J.A., 1995. Modeling volatility dynamics. In: Hoover, K. (Ed.), Macroeconometrics: Developments, Tensions and Prospects. InKluwer Academic Publishers, Amsterdam, pp. 427-472.

Durbin, J., Koopman, S.J., 1997. Monte Carlo maximum likelihood for non-Gaussian state space models. Biometrika 84, 669-684.

Durbin, J., Koopman, S.J., 2002. A simple and efficient simulation smoother for state space time series analysis. Biometrika 3, 603-616.

Elder, J., 2004. Another perspective on the effects of inflation uncertainty. Journal of Money, Credit, and Banking 36 (5), 911-928.
Engle, R., 1982. Autoregressive conditional heteroscedasticity with estimates of the variance of U.K. inflation. Econometrica 50, 987-1008.

Evans, M., 1991. Discovering the link between inflation rates and inflation uncertainty. Journal of Money, Credit, and Banking 23, 169-184.

Evans, M., Wachtel, P., 1993. Inflation regimes and the sources of inflation uncertainty. Journal of Money, Credit, and Banking 25 (3, Part 2), 475-511.

Fischer, S., 1981. Towards an understanding of the costs of inflation II. CarnegieRochester Conference Series on Public Policy, pp. 5-42.

Friedman, M., 1977. Nobel lecture: inflation and unemployment. Journal of Political Economy 85, 451-472.

Gallant, A.R., Hsieh, D.A., Tauchen, G.E., 1997. Estimation of stochastic volatility models with diagnostics. Journal of Econometrics 81, 159-192.

Geweke, J., 1994. Bayesian comparison of econometric models. Working Paper, Federal Reserve Bank of Minneapolis, Minnesota. 21.

Ghysels, E., Harvey, A.C., Renault, E., 1996. Stochastic volatility. In: Maddala, G.S., Rao, C.R. (Eds.), Handbook of Statistics, 14. North-Holland, Amsterdam.

Golob, John E., 1994. Does inflation uncertainty increase with inflation? Federal Reserve Bank of Kansas City, Economic Review, Third Quarter.

Grier, K., Perry, M.J., 1998. On inflation and inflation uncertainty in the G7 countries. Journal of International Money Finance 17, 671-689.

Grier, K., Perry, M.J., 2000. The effects of real and nominal uncertainty on inflation and output growth: some GARCH-M evidence. Journal of Applied Econometrics 15 (1), 445-458.

Hamilton, J.D., 1994. Time Series Analysis. Princeton University press, Princeton, N.J.

Harvey, A.C., Ruiz, E., Shephard, N., 1994. Multivariate stochastic variance models. Review of Economic Studies 61, 247-264.

Hol, E., Koopman, S.J., 2000. Forecasting the variability of stock index returns with stochastic volatility models and implied volatility. http://www.timbergen.nl.

Holland, S., 1993. Comment on inflation regimes and the sources of inflation uncertainty. Journal of Money, Credit, and Banking 25, 514-520.

Holland, S., 1995. Inflation and uncertainty: tests for temporal ordering. Journal of Money Credit Banking 27, 827-837.

Huybens, E., Smith, B., 1999. Inflation, financial markets and long-run real activity. Journal of Monetary Economics 43, 283-315.

Jacquier, E., Polson, N.G., Rossi, P.E., 1994. Bayesian analysis of stochastic volatility models (with discussion). Journal of Business and Economics Statistics 12, 371-389.

Johnson, D., 2002. The effect of inflation targeting on the behavior of expected inflation: evidence from an 11 country panel. Journal of Monetary Economics 49, 1521-1538.

Kim, S., Shephard, N., Chib, S., 1998. Stochastic volatility: likelihood inference and comparison with ARCH models. Review of Economic Studies 65, 361-394.

Koop, G., Pesaran, M.H., Potter, S.M., 1996. Impulse response analysis in nonlinear multivariate models. Journal of Econometrics, Elsevier 74 (1), 119-147.

Koopman, S.J., Uspensky, E.H., 2002. The stochastic volatility in mean model: empirical evidence from international stock markets. Journal of Applied Econometrics 17, 667-689.

Koopman, S.J., Shephard, N., Doornik, J.A., 1999. Statistical algorithms for models in state space form using SsfPack 2.2. Econometrics Journal 2, 113-166.

Melino, A., Turnbull, S.M., 1990. Pricing foreign currency options with stochastic volatility. Journal of Econometrics 45, 239-265.

Okun, A., 1971. The mirage of steady inflation. Brookings Papers on Economic Activity 2, 485-498.

Pagan, A., Ullah, A., 1988. The econometric analysis of models with risk term. Journal of Applied Econometrics 3, 87-105.

Potter, S., 2000. Nonlinear impulse response functions. Journal of Economic Dynamics \& Control 24, 1425-1446.

Ripley, B., 1987. Stochastic simulation. Wiley, New York.

Ruiz, E., 1994. Quasi-maximum likelihood estimation of stochastic volatility models. Journal of Econometrics 63, 289-306.

Shepard, N., 1996. Statistical aspects of ARCH and stochastic volatility. In: Cox, D.R., Hinkley, D.V., Barndorff-Nielsen, O.E. (Eds.), Time series models in econometrics, finance and other fields, 65. Chapman and Hall, Monographs on Statistics and Applied Probability, pp. 1-67.

Shephard, N., Pitt, M., 1997. Likelihood analysis of non-Gaussian measurement time series. Biometrika 84, 653-667.

Taylor, S.J., 1994. Modelling stochastic volatility: a review and comparative study. Mathematical Finance 4, 183-204.

Wooldridge, J.M., 1991. On the applications of robust, regression-based diagnostics to models of conditional means and conditional variances. Journal of Econometrics 47, $5-46$.

Zarnowitz, V., Lambros, L., 1987. Consensus and uncertainty in economic prediction. Journal of Political Economy 95, 591-621. 